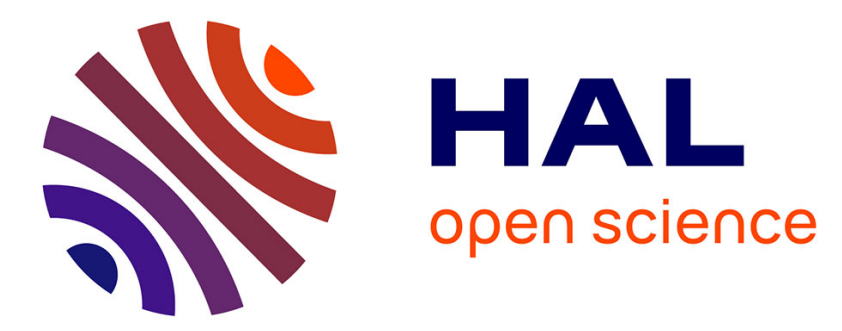

\title{
Models of the longitudinal distribution of ring area as a function of tree and stand attributes for four major Canadian conifers
}

\author{
Francesco Cortini, Arthur Groot, Cosmin Filipescu
}

\section{- To cite this version:}

Francesco Cortini, Arthur Groot, Cosmin Filipescu. Models of the longitudinal distribution of ring area as a function of tree and stand attributes for four major Canadian conifers. Annals of Forest Science, 2013, 70 (6), pp.637-648. 10.1007/s13595-013-0305-9 . hal-01201508

\author{
HAL Id: hal-01201508 \\ https://hal.science/hal-01201508
}

Submitted on 17 Sep 2015

HAL is a multi-disciplinary open access archive for the deposit and dissemination of scientific research documents, whether they are published or not. The documents may come from teaching and research institutions in France or abroad, or from public or private research centers.
L'archive ouverte pluridisciplinaire HAL, est destinée au dépôt et à la diffusion de documents scientifiques de niveau recherche, publiés ou non, émanant des établissements d'enseignement et de recherche français ou étrangers, des laboratoires publics ou privés. 


\title{
Models of the longitudinal distribution of ring area as a function of tree and stand attributes for four major Canadian conifers
}

\author{
Francesco Cortini - Arthur Groot • Cosmin N. Filipescu
}

Received: 18 December 2012 / Accepted: 28 May 2013 /Published online: 6 June 2013

(C) INRA and Springer-Verlag France 2013

\begin{abstract}
- Context It is widely accepted that ring area increment generally increases from the tree apex to the crown base and is more-or-less constant below the crown base (Pressler's law), but few quantitative models of this distribution have been developed.

- Aims The aim of this study was to develop a model of ring area increment using easily obtained crown features and other tree or stand characteristics in order to further the understanding and prediction of tree growth, form, and wood quality.

- Methods The models were fit to stem analysis observations from white spruce, black spruce, balsam fir, and lodgepole pine. - Results In the final model, which includes tree crown and stand variables, ring area increment within the crown region was slightly curvilinear, the slope of ring area increment below the crown was non-zero, and the effect of butt swell was appreciable up-to a relative height of 0.10 .

- Conclusions The high accuracy of the mixed effects model suggests that the three-component model form is appropriate for describing ring area profiles, whereas some tree-to-tree variation remains unexplained. The tree and stand variables
\end{abstract}

Handling Editor: Jean-Michel Leban

Contributions of the co-authors Francesco Cortini: data analysis, modeling, and writing

Arthur Groot: experimental design, modeling, and writing

Cosmin N. Filipescu: modeling and writing

F. Cortini $(\bowtie) \cdot$ C. N. Filipescu

Natural Resources Canada, Canadian Wood Fibre Centre,

506 West Burnside Rd, Victoria, British Columbia V8Z 1M5, Canada

e-mail: fcortini@gmail.com

C. N. Filipescu

e-mail: cfilipes@NRCan.gc.ca

\section{A. Groot}

Natural Resources Canada, Canadian Wood Fibre Centre, 1219

Queen St. E, Sault Ste. Marie, ON P6A 2E5, Canada

e-mail: agroot@NRCan.gc.ca used in these models can be easily measured in the field or obtained from remote sensing techniques.

Keywords Ring area $\cdot$ Tree growth $\cdot$ Crown attributes . Stand attributes $\cdot$ Three component model $\cdot$ Pressler's law

\section{Introduction}

Tree stem form and some aspects of wood quality are the result of the accumulation of many annual sheaths of xylem laid down along the tree stem. Not surprisingly, foresters and forest scientists developed an early interest in the longitudinal distribution of annual xylem increment. A characteristic pattern was frequently observed, and in the nineteenth century, M.R. Pressler published what has become known as Pressler's law: "Ring area growth (cross-sectional area of a single annual increment) at any one point on the stem is proportional to the quantity of foliage above this point" (Pressler 1864 as cited by Larson 1963). Larson (1963) outlined nutritional, water conduction, mechanistic, and hormonal theories to account for the distribution of annual growth along the stem and its cumulative resultant, tree stem form. The relative influence and the interaction of these mechanisms on growth distribution has not yet been satisfactorily resolved, although the effect of mechanical stress appears to dominate (Gaffrey and Sloboda 2001).

Even if the causal mechanisms are not fully understood, the general pattern of ring area distribution summarized in Pressler's law has long been widely accepted (Farrar 1961; Hyink and Zedaker 1987). Published observations typically show an increase in ring area from the tree apex to a point near the crown base, below which ring area is more-or-less constant until a further increase in the butt zone (e.g., Weiner 1984; Ottorini et al. 1996; Bevilacqua et al. 2005; Ikonen et al. 2006). Several individual tree growth models use Pressler's law to distribute growth along the stem (Mitchell 
1975; Houllier et al. 1995; Barczi et al. 2008). The break point in the ring area profile near the crown base makes it possible to reconstruct crown recession via stem analysis (Ottorini et al. 1996; Deleuze and Houllier 1995).

Pressler's law has been criticized as an oversimplification of the actual patterns of ring area distribution that occur under varying environmental conditions (Deleuze and Houllier 2002). Pressler's law completely ignores the pronounced increase in ring area that is commonly observed near the base of the tree. It also does not account for frequent observations of decreases or increases in ring area below the crown base (e.g., Bevilacqua et al. 2005).

The distribution of annual growth along the tree stem is of considerable significance for wood quality. Since properties such as latewood proportion and specific gravity are related to growth ring width for certain species such as conifers with gradual transition between earlywood and latewood (Saranpää 2003), ring width is often used as an indicator of wood quality (Panshin and de Zeuw 1970). Stem taper, which integrates the distributions of ring area for all the years of a tree's life, is also a key determinant of wood quality (Jozsa and Middleton 1994). In order to more closely couple growth and wood quality, Houllier et al. (1995) developed a growth model that resolved individual ring distributions based on Pressler's law. They recognized that Pressler's law was not a fully adequate description and recommended that this aspect of the model be improved in the future.

Despite the importance of and the uncertainty about patterns of ring area increment along the tree stem, there have been surprisingly few efforts to develop models that are more general than Pressler's law. An early polynomial model resolved the contribution of individual branches to loblolly pine stem growth and predicted a slight decline in area increment below the crown base (Labyak and Schumacher 1954). Courbet (1999) developed a model comprising three nonlinear and linear segments, corresponding to the within crown, below crown, and butt regions of the tree stem. The general model was constrained to pass through a known ring area increment at breast height. Kershaw and Maguire (2000) drew on pipe model theory to relate area increment to current foliage area in Tsuga heterophylla and Abies balsamea. Finally, Deleuze and Houllier (2002) derived a carbon diffusion and consumption model to describe area increment along the stem for individual Picea abies trees. The models that have been developed to date either (1) require detailed information on foliage distribution or breast height ring area that are not part of readily available data or (2) are fitted only to individual trees.

The objective of this study was to develop a general model of ring area distribution using easily obtained crown features and other tree or stand characteristics. We developed this model using five sets of data that included stem analysis, tree crown, and stand attributes. Although the five datasets represents four different species, the main objective of this study is to investigate the underlying biological characteristics of ring area increments beyond the species specific differences.

\section{Materials and methods}

\subsection{Study data description}

The stem analysis data used for this study comprises five datasets from across Canada (Fig. 1), and include four tree species: white spruce (Picea glauca (Moench) Voss), black spruce (Picea mariana (Mill.) B.S.P.), balsam fir (A. balsamea (L.) Mill.), and lodgepole pine (Pinus contorta Dougl.). Much of the data were obtained from density management (initial spacing or thinning) experiments (Table 1), which provided a wide range of crown characteristics. The number of destructively sampled trees in each dataset ranged between 23 and 120 for a total of 263 trees (Table 2). Crosssectional disks were obtained along the bole, at and below $1.3 \mathrm{~m}$ height and at intervals of either 1 to $2 \mathrm{~m}$ or at $4-11$ approximately equally spaced locations above breast height. The resulting number of disks per tree ranged between seven and 26 with an average of 11.7. Rings on disks were measured using the Windendro system (Regent Instruments, QC, Canada) on four radii corresponding to the greatest disk

Fig. 1 Location of study sites

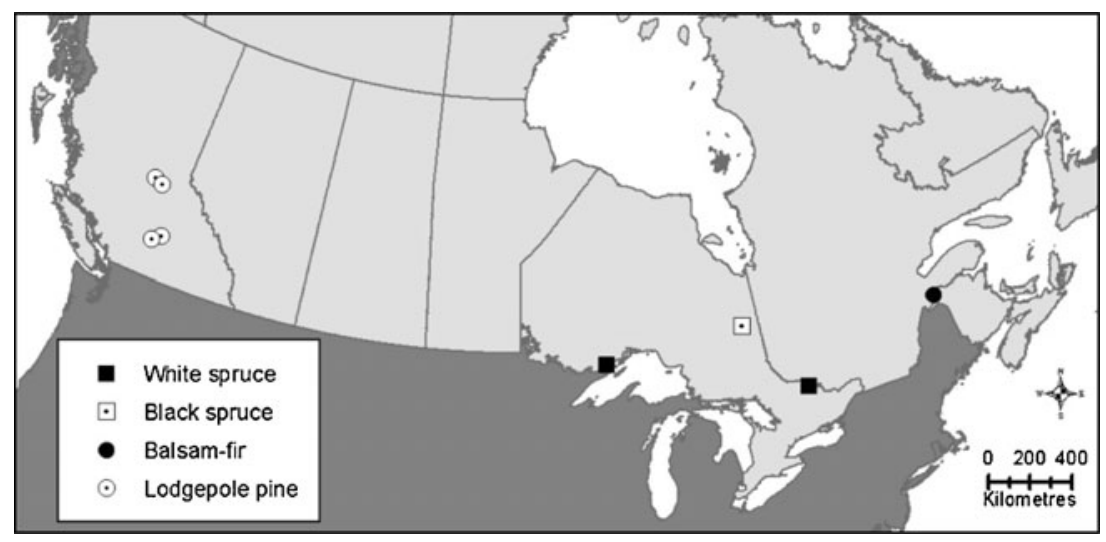




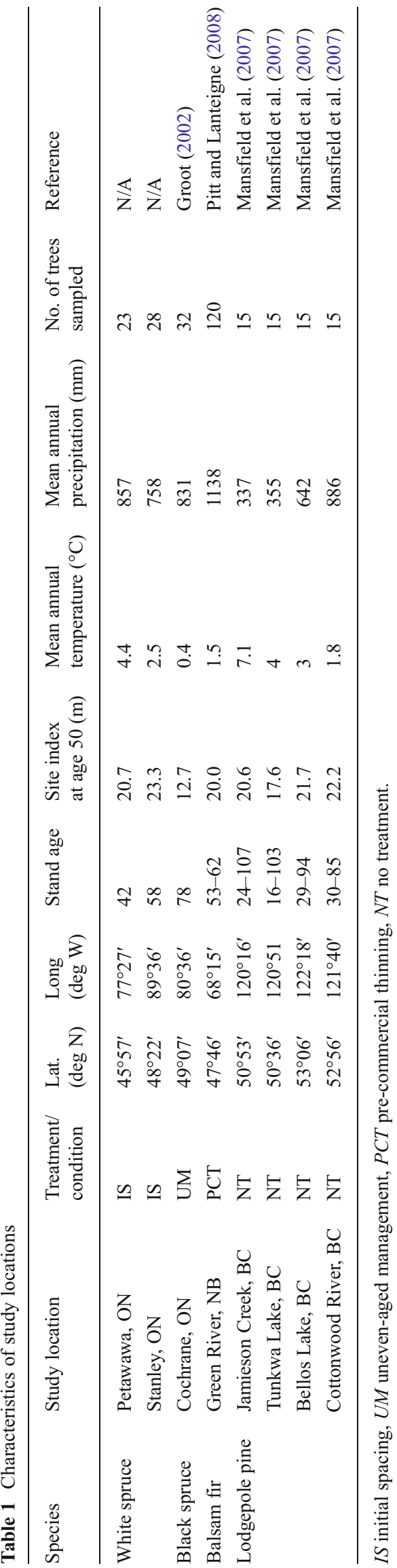

diameter through the pith and its perpendicular diameter through the pith (spruces and fir). For pine, rings were measured on the two radii from the pith that corresponded to half the mean disk diameter measured using a diameter tape. For all species, disk area for individual years was computed from the geometric mean of the radii and the formula for a circle. Average annual ring area increment was calculated for the last three complete growth years available, from the difference in disk areas for those years. These methods provide unbiased estimates of area for disks that are close to circular in shape with centered pith, and can provide low error $(<10 \%)$ estimates even for more variable disks from healthy trees (Cruickshank 2002). Estimates of past tree height were calculated from the number of growth rings above the highest section point following the methodology described by Newberry (1991). Crown and stand attributes including crown radius, crown length, stand dominant height, and basal area of the trees larger than the subject tree (within the plot) were measured for each tree species. Site index values (at age 50) varied only for lodgepole pine because trees were selected from multiple locations.

\subsection{Model development}

Initial fitting was attempted with a three-segmented polynomial model, of the type used to describe stem taper by Max and Burkhart (1976). Results were unsatisfactory, however, with fitted models producing unrealistic ring area distributions and join points. Subsequent analysis suggested that a three component model structure was effective for modeling ring area increments along the stem. Crown length and crown base were adjusted by an effective crown factor because inspection of the data indicated that the breakpoint typically occurs above the crown base. The effective crown factor was calculated in a separate step because preliminary tests could not achieve convergence for models where the effective crown factor was integrated as a join point parameter.

The base model comprises three components: (1) the crown component, which is represented by a power function of the distance of the disk from the apex (at and below the effective crown base, this distance is set to the effective crown length); (2) the middle component, which is represented by a linear function of the distance of the disk below the effective crown base and which equals zero above the effective crown base; and (3) the butt swell component, which is represented by an exponential function of relative disk height (RDH; i.e., disk height divided by the total height of the tree), as follows:

$$
\begin{aligned}
Y_{i j}= & \left(a_{0}+z_{n} \times d_{n}\right) \times \mathrm{DIC}_{i j}{ }^{a_{1}}+ \\
& +\left(b_{0}+s_{n} \times d_{n}\right) \times \mathrm{DBCB}_{i j}+ \\
& +\left(c_{0}\right) \times \operatorname{EXP}\left(c_{1} \times \mathrm{RDH}_{i j}\right)+\varepsilon_{i j}
\end{aligned}
$$


Table 2 Basic statistical information of selected variables for each species

\begin{tabular}{|c|c|c|c|c|c|}
\hline Species & Variable & Minimum & Mean & Maximum & Standard deviation \\
\hline \multirow[t]{8}{*}{ White Spruce (trees, 51 and disks, 927) } & Annual ring area increment $\left(\mathrm{cm}^{2}\right)$ & 0.1 & 6.8 & 36.7 & 5.9 \\
\hline & Tree height (m) & 10.7 & 18.0 & 24.0 & 3.3 \\
\hline & Crown length (m) & 2.6 & 7.0 & 12.2 & 2.4 \\
\hline & Crown radius $(\mathrm{m})$ & 0.6 & 1.7 & 3.5 & 0.7 \\
\hline & Stand dominant height $(\mathrm{m})$ & 15.9 & 21.2 & 26.4 & 3.5 \\
\hline & Basal area of larger trees $\left(\mathrm{m}^{2} \mathrm{ha}^{-1}\right)$ & 0.0 & 29.0 & 73.6 & 19.5 \\
\hline & Crown ratio & 0.17 & 0.39 & 0.79 & 0.14 \\
\hline & Diameter at breast height $(\mathrm{cm})$ & 10.4 & 25.1 & 40 & 7.58 \\
\hline \multirow[t]{8}{*}{ Black Spruce (trees, 32 and disks, 381} & Annual ring area increment $\left(\mathrm{cm}^{2}\right)$ & 0.1 & 2.9 & 14.0 & 1.6 \\
\hline & Tree height (m) & 6.7 & 12.4 & 16.6 & 2.1 \\
\hline & Crown length (m) & 3.7 & 7.5 & 11.6 & 2.0 \\
\hline & Crown radius $(\mathrm{m})$ & 0.7 & 1.0 & 1.4 & 0.2 \\
\hline & Stand dominant height (m) & 12.1 & 14.5 & 17.1 & 1.4 \\
\hline & Basal area of larger trees $\left(\mathrm{m}^{2} \mathrm{ha}^{-1}\right)$ & 0.0 & 9.8 & 30.7 & 8.5 \\
\hline & Crown ratio & 0.3 & 0.6 & 0.9 & 0.1 \\
\hline & Diameter at breast height $(\mathrm{cm})$ & 9.5 & 15.3 & 23.9 & 3.1 \\
\hline \multirow[t]{8}{*}{ Balsam fir (trees, 120 and disks, 1077) } & Annual ring area increment $\left(\mathrm{cm}^{2}\right)$ & 0.1 & 3.8 & 24.8 & 3.1 \\
\hline & Tree height (m) & 10.3 & 16.7 & 22.2 & 2.8 \\
\hline & Crown length (m) & 2.1 & 6.6 & 18.2 & 2.8 \\
\hline & Crown radius $(\mathrm{m})$ & 0.5 & 1.2 & 2.3 & 0.4 \\
\hline & Stand dominant height (m) & 19.1 & 21.0 & 22.8 & 1.1 \\
\hline & Basal area of larger trees $\left(\mathrm{m}^{2} \mathrm{ha}^{-1}\right)$ & 1.5 & 27.7 & 51.7 & 14.0 \\
\hline & Crown ratio & 0.1 & 0.4 & 0.9 & 0.1 \\
\hline & Diameter at breast height $(\mathrm{cm})$ & 9.6 & 18.8 & 31 & 5.8 \\
\hline \multirow[t]{9}{*}{ Lodgepole pine (trees, 60 and disks, 702) } & Annual ring area increment $\left(\mathrm{cm}^{2}\right)$ & 0.1 & 6.3 & 35.6 & 4.7 \\
\hline & Tree height (m) & 6.0 & 20.2 & 29.1 & 6.1 \\
\hline & Crown length $(\mathrm{m})$ & 3.9 & 9.0 & 17.8 & 3.1 \\
\hline & Crown radius $(\mathrm{m})$ & 0.4 & 1.6 & 3.3 & 0.6 \\
\hline & Stand dominant height $(\mathrm{m})$ & 5.7 & 20.9 & 31.0 & 5.9 \\
\hline & Basal area of larger trees $\left(\mathrm{m}^{2} \mathrm{ha}^{-1}\right)$ & 0.0 & 11.4 & 45.3 & 13.3 \\
\hline & Site index at age $50(\mathrm{~m})$ & 13.5 & 20.3 & 26.9 & 2.8 \\
\hline & Crown ratio & 0.2 & 0.5 & 0.9 & 0.2 \\
\hline & Diameter at breast height $(\mathrm{cm})$ & 4.6 & 17.6 & 32.7 & 6.7 \\
\hline
\end{tabular}

Where: $Y_{i j}$ is theannual average ring area increment (in square centimeters) of disk $j$ in tree $i$; $\mathrm{DIC}_{i j}$ is the distance inside crown (in meters); $\mathrm{DIC}_{i j}$ is the tree height-disk height for disk height>effective crown base: $\mathrm{DIC}_{i j}$ is the tree height - effective crown base for disk height $\leq$ effective crown base; effective crown base $=$ tree height $-($ tree height - measured crown base) $\times$ effective crown factor; $\mathrm{DBCB}_{i j}$ is the distance below effective crown base (in meters): $\mathrm{DBCB}_{i j}=0$ for disk height $>$ effective crown base; $\mathrm{DBCB}_{i j}=$ effective crown base - disk height for disk height $\leq$ effective crown base; $\mathrm{RDH}_{i j}=$ $\mathrm{RDH}$ (i.e., disk height/tree height averaged over the last 3 years); $d_{n}$ is the indicator variables with $n=1,2$, or 3 for black spruce, balsam fir, and lodgepole pine, respectively (with white spruce as the reference), for the crown component and the middle component (i.e., $d_{n}=1$ for the concerned species, and $d_{n}=0$ for the other species); $a_{m}, b_{m}$, $c_{m}, z_{n}$, and $s_{n}$ are fixed effects parameters; and $\varepsilon_{i j}$ is the residual error.

Indicator variables were used for each component to capture the variability between species with white spruce used as the reference. Preliminary analysis (i.e., $F$ tests) indicated that white spruce data from the Petawawa installation and the Stanley installation could be combined. Moreover, the indicator variables for the butt swell component were removed because they were not significantly different between species $(\alpha<0.05)$.

The effective crown factor was determined by fitting a mixed-effects version of Eq. 1 inclusive of tree as a random 
subject in order to account for correlated sources of variability at the tree level. Crown factor values ranging from 0.5 to 1.2 were tested.

The base model is essentially equivalent to Pressler's Law if the coefficients $\left(b_{0}+s_{n} * d_{n}\right)$ and $\left(c_{0}\right)$ are both 0 ; other values of these coefficients yield a more general model of ring area distribution. It should be noted that the three component model is not a three segmented model: the crown component and the butt swell component are additive along the entire length of the tree, and the middle component is additive below the crown base.

In a subsequent step, tree attributes such as crown length, crown radius, crown ratio (i.e., crown length/tree height averaged over the last 3 years), and diameter at breast height were added to the base model, and only those variables that contributed significantly $(\alpha<0.05)$ to the model were retained.

Furthermore, we tested other tree attributes relative to the stand characteristics such as relative tree height (i.e., tree height averaged over the last 3 years/stand dominant tree height), basal area of the larger trees, and site index at age 50 and only those variables that contributed significantly $(\alpha<$ $0.05)$ to the model were retained.

In a final step, mixed effect models analysis including tree as a random subject was carried out in order to account for correlated sources of variability at the tree level. We then included an appropriate variance function and correlation structure which allowed us to model heteroscedasticity and dependence among within group errors (Pinherio and Bates 2000).

The models were compared using several criteria including: (1) residual plots, (2) the coefficient of determination (Pseudo- $R^{2}$ ), (3) Akaike's information criterion (AIC; Burnham and Anderson 1998), (4) the root mean square error (RMSE) of ring area increment (i.e., absolute values and percentage relative to the average ring area), and (5) tree level RMSE of volume increment (in percent). Volume increment was calculated as the integration of the ring area profile. Parameter estimation for the fixed effects models and the mixed effects model was completed using the NLMIXED procedure in SAS statistical package (version 9.2; SAS Institute Inc., Cary, NC) and the NLME statistical package (Pinheiro et al. 2009) in R (version 2.15.1); the $\mathrm{R}$ foundation for Statistical Computing).

\section{Results}

The effective crown factor that provided the best model fit (lowest AIC) was 0.63 . This implies that the effective crown base was approximately one third of the crown length above the measured crown base.

When tree attributes were added to the base model the following equation provided the best fit:

$$
\begin{aligned}
Y_{i j}= & \left(\left(a_{0}+z_{n} \times d_{n}\right)+a_{2} \times \mathrm{CrL}_{i}+a_{3} \times \mathrm{CrR}_{i}+a_{4} \times \mathrm{CrT}_{i}\right) \times \mathrm{DIC}_{i j}{ }^{a_{1}}+ \\
& +\left(\left(b_{0}+s_{n} \times d_{n}\right)+b_{1} \times \mathrm{CrR}_{i}+b_{2} \times \mathrm{CrT}_{i}\right) \times \mathrm{DBCB}_{i j}+ \\
& +\left(c_{0}+c_{2} \times \mathrm{CrL}_{i}\right) \times \operatorname{EXP}\left(c_{1} \times \mathrm{RDH}_{i j}\right)+\varepsilon_{i j}
\end{aligned}
$$

Where: $\mathrm{CrL}_{i}$ is crown length (in meters); $\mathrm{CrR}_{i}=$ crown radius (in meters); $\mathrm{CrT}_{i}$ is the crown ratio for tree $i$.

When tree attributes relative to the stand characteristics were added to the base model the following equation provided the best fit:

$$
\begin{aligned}
Y_{i j}= & \left(\left(a_{0}+z_{n} \times d_{n}\right)+a_{2} \times \mathrm{CrL}_{i}+a_{3} \times \mathrm{CrR}_{i}+a_{4} \times \mathrm{CrT}_{i}+a_{5} \times \mathrm{RTH}_{i}+a_{6} \times \mathrm{BALT}_{i}+\left(t_{n} \times a_{7}\right) \times \mathrm{SI}_{i}\right) \times \mathrm{DIC}_{i j} a_{1}+ \\
& +\left(\left(b_{0}+s_{n} \times d_{n}\right)+b_{1} \times \mathrm{CrR}_{i}+b_{2} \times \mathrm{CrT}_{i}+b_{3} \times \mathrm{RTH}_{i}\right) \times \mathrm{DBCB}_{i j}+\left(c_{0}+c_{2} \times \mathrm{CrL}_{i}\right) \times \mathrm{EXP}\left(c_{1} \times \mathrm{RDH}_{i j}\right)+\varepsilon_{i j}
\end{aligned}
$$

Where: $\mathrm{RTH}_{i}$ is a relative tree height for tree $i$ (i.e., tree height averaged over the last 3 years/stand dominant tree height); $\mathrm{BALT}_{i}$ is the basal area of larger trees (in square meters per hectare); $\mathrm{SI}_{i}$ is the eight Site Index at age 50 (in meters) of stand for tree $i$; $t_{n}=$ indicator variable by tree species relative to Site Index values (in meters; i.e., $t=1$ for lodgepole pine, and $t=0$ for the other species).

When random effects and the variance-covariance structure were added to the model the following equation provided the best fit:

$$
\begin{aligned}
Y_{i j} & =\left(\left(\left(a_{0}+\mathrm{ua}_{0 i}\right)+z_{n} \times d_{n}\right)+a_{2} \times \mathrm{CrL}_{i}+a_{3} \times \mathrm{CrR}_{i}+a_{4} \times \mathrm{CrT}_{i}+a_{5} \times \mathrm{RTH}_{i}+a_{6} \times \mathrm{BALT}_{i}+\left(t_{n} \times a_{7}\right) \times \mathrm{SI}_{i}\right) * \mathrm{DIC}_{i j} a_{1}+ \\
& \left.+\left(\left(\left(b_{0}+\mathrm{ub}_{0 i}\right)+s_{n} \times d_{n}\right)+b_{1} \times \mathrm{CrR}_{i}+b_{2} \times \mathrm{CrT}_{i}+b_{3} \times \mathrm{RTH}_{i}\right) \times \mathrm{DBCB}_{i j}++\left(\left(c_{0}+\mathrm{uc}_{0 i}\right)+c_{2}\right) \times \mathrm{CrL}_{i}\right) \\
& \times \operatorname{EXP}\left(c_{1} \times \mathrm{RDH}_{i j}\right)+\varepsilon_{i j}
\end{aligned}
$$

Where: $\mathrm{ua}_{0 i}, \mathrm{ub}_{0 \mathrm{i}}$, and $\mathrm{uc}_{0 i}$ are random effects (normally distributed with mean zero and an unknown variance component) relative to the crown component, the middle component, and the butt swell component, respectively, for 


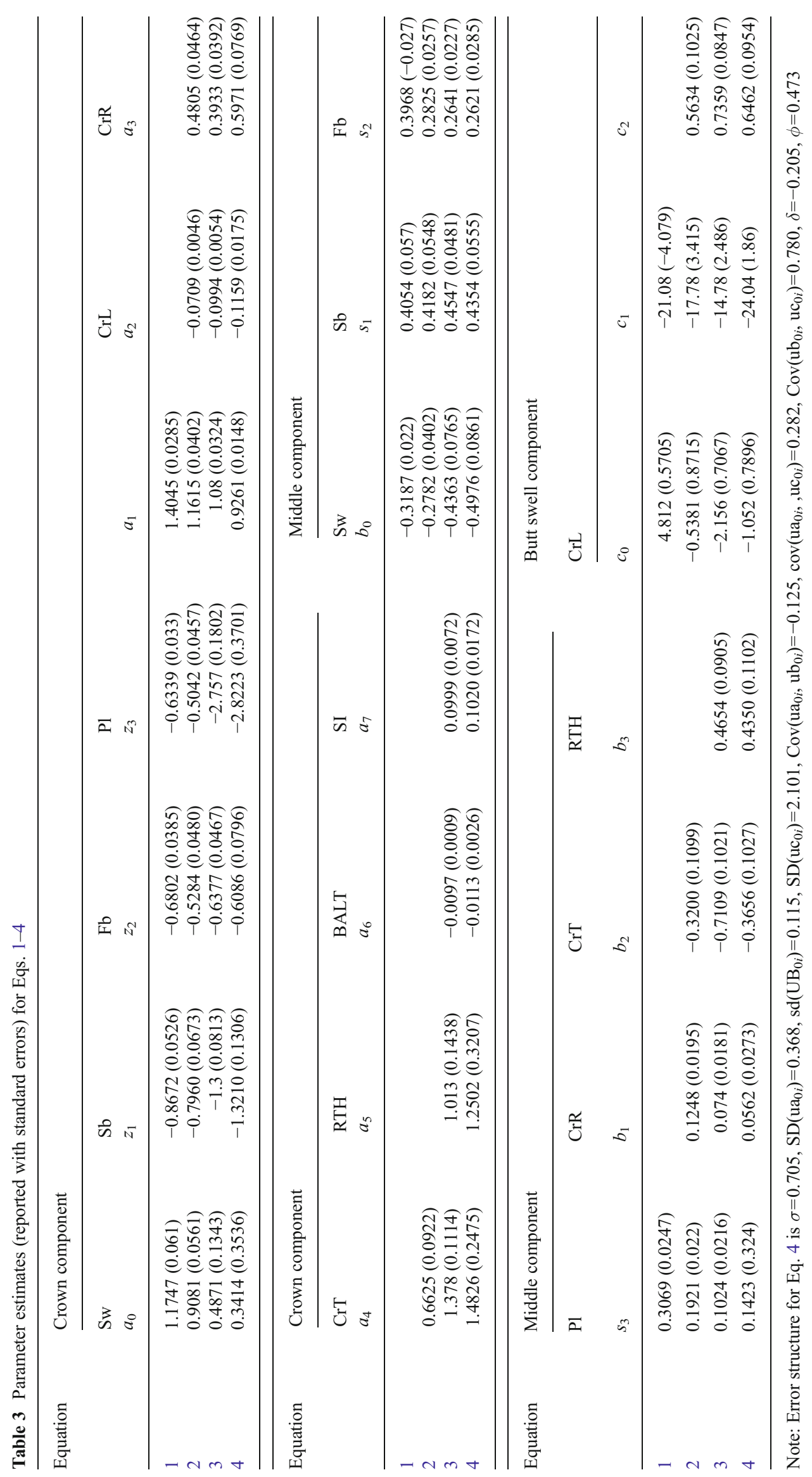


Table 4 Goodness of fit for Eqs. 1-4

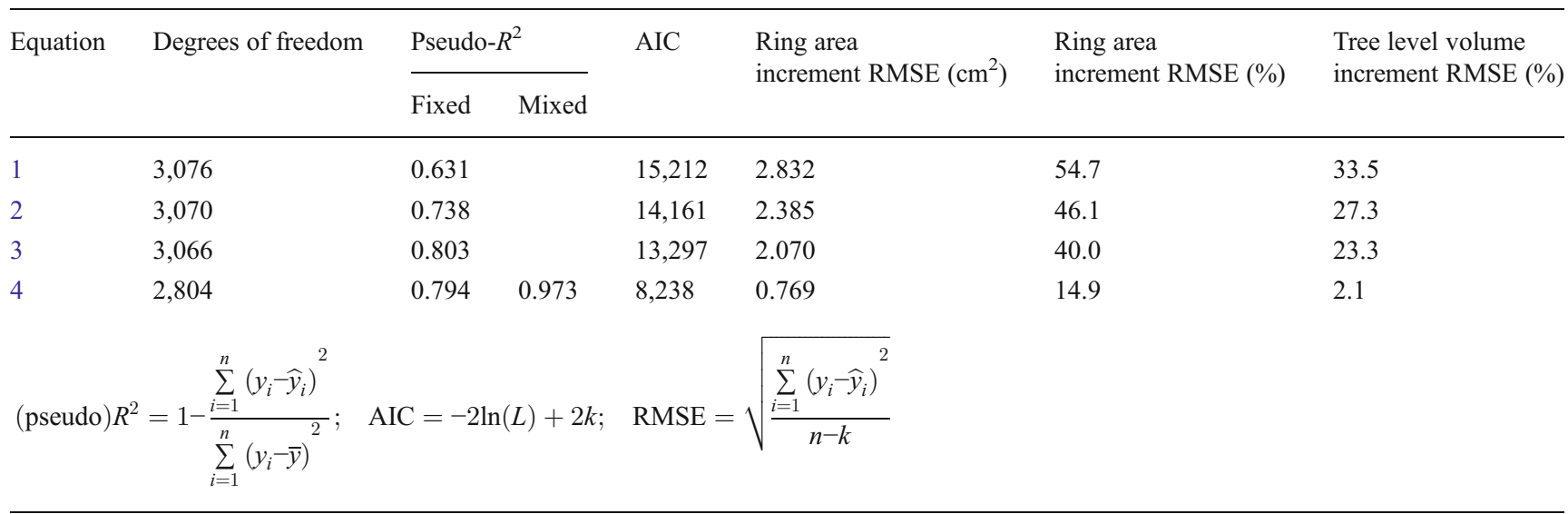

$y_{i}$ observed values, $\widehat{y}_{i}$ predicted values, $\bar{y}$ average, $n$ sample size, $k$ number of mode parameters, $\ln (L)$ logarithm of the likelihood function

tree $i$; the error structure is defined by an unstructured variance-covariance matrix of random effects $\mathrm{ua}_{0 \mathrm{i}}, \mathrm{ub}_{0 \mathrm{i}}$ and $\mathrm{uc}_{0 \mathrm{i}}$, with a power variance function $G_{i}\left(\mathrm{ua}_{0 i}, \mathrm{ub}_{0 i}, \mathrm{uc}_{0 i}\right.$, and $\delta)=\left|\mathrm{RDH}_{i j}\right|^{\delta}$, and a serial correlation function $\Gamma \mathrm{i}(\varepsilon)=\mathrm{CAR}(1)$ to account for correlation between disks $j$ within each tree $i$.

The first component of Eqs. 1 to 4 described increasing ring area within the crown region, from the tree apex to the effective crown base, and then a constant ring area below this point. The power function coefficient $\left(a_{1}\right)$ in this component was 0.9261 for Eq. 4, which indicates that the relationship between ring area increment and the distance inside the crown was slightly curvilinear (Table 3 ). The power function coefficient increased moving toward simpler models (i.e., 1.08 for Eq. 3; 1.1615 for Eq. 2; and 1.4045 for Eq. 1). In Eqs. 3 and 4, ring area within the crown increased with crown radius, crown ratio, relative tree height and site index (for lodgepole pine), and decreased with crown length and basal area of larger trees. With all other factors equal, ring area was greatest for white spruce, followed by balsam fir, black spruce and lodgepole pine, respectively (Table 3).
Fig. 2 Scatter plots of observed ring area increment (in square centimeters) against predicted ring area increment (in square centimeters) together with the $1: 1$ thin-black line and the fitted Lowess thick-red line (i.e., graph $a$ for Eq. 3 and graph $c$ for Eq. 4), and scatter plots of residuals (in square centimeters) against predicted ring area increment (in square centimeters) together with the fitted Lowess thick-red line (i.e., graph $b$ for Eq. 3 and graph $d$ for Eq. 4)
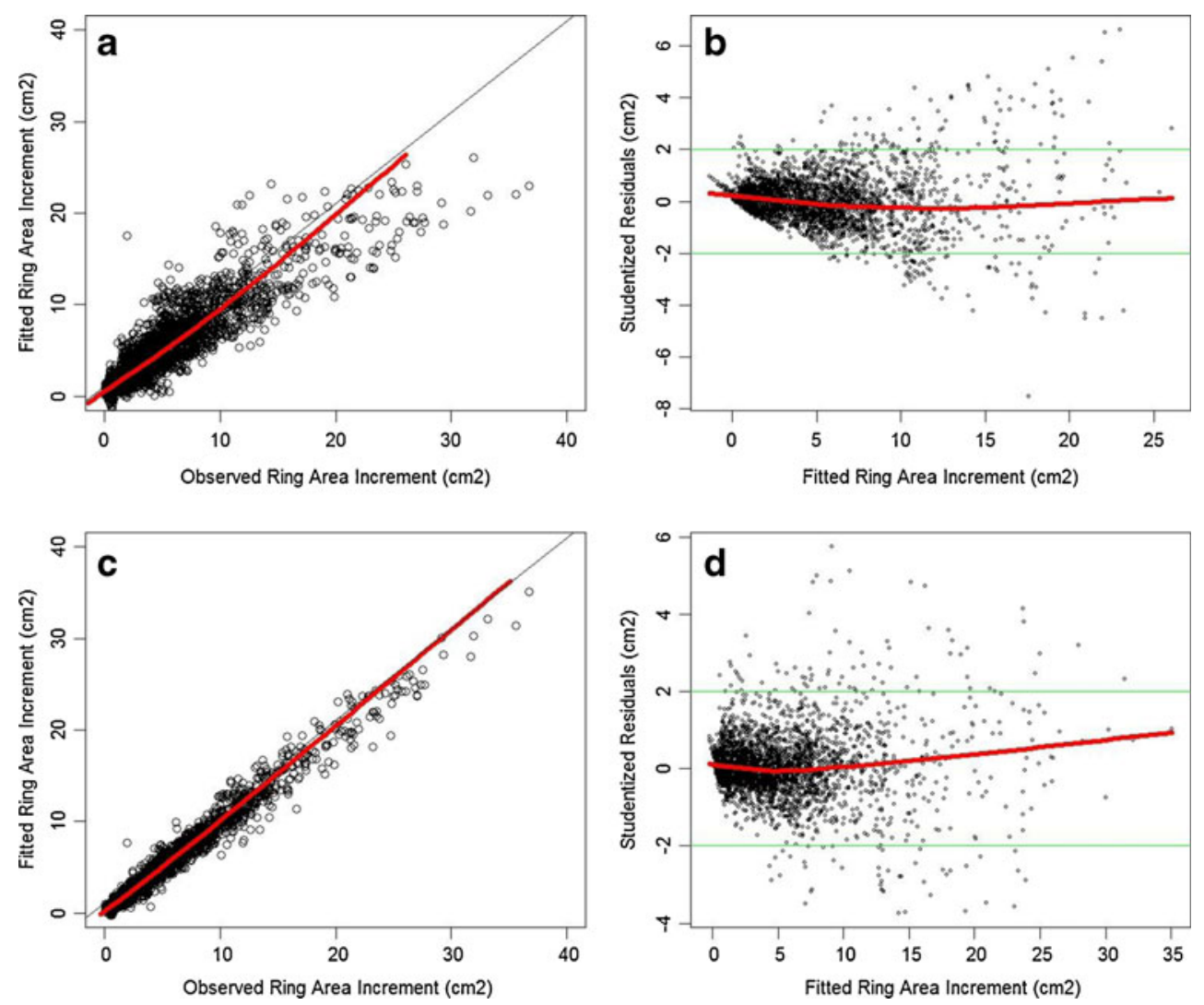


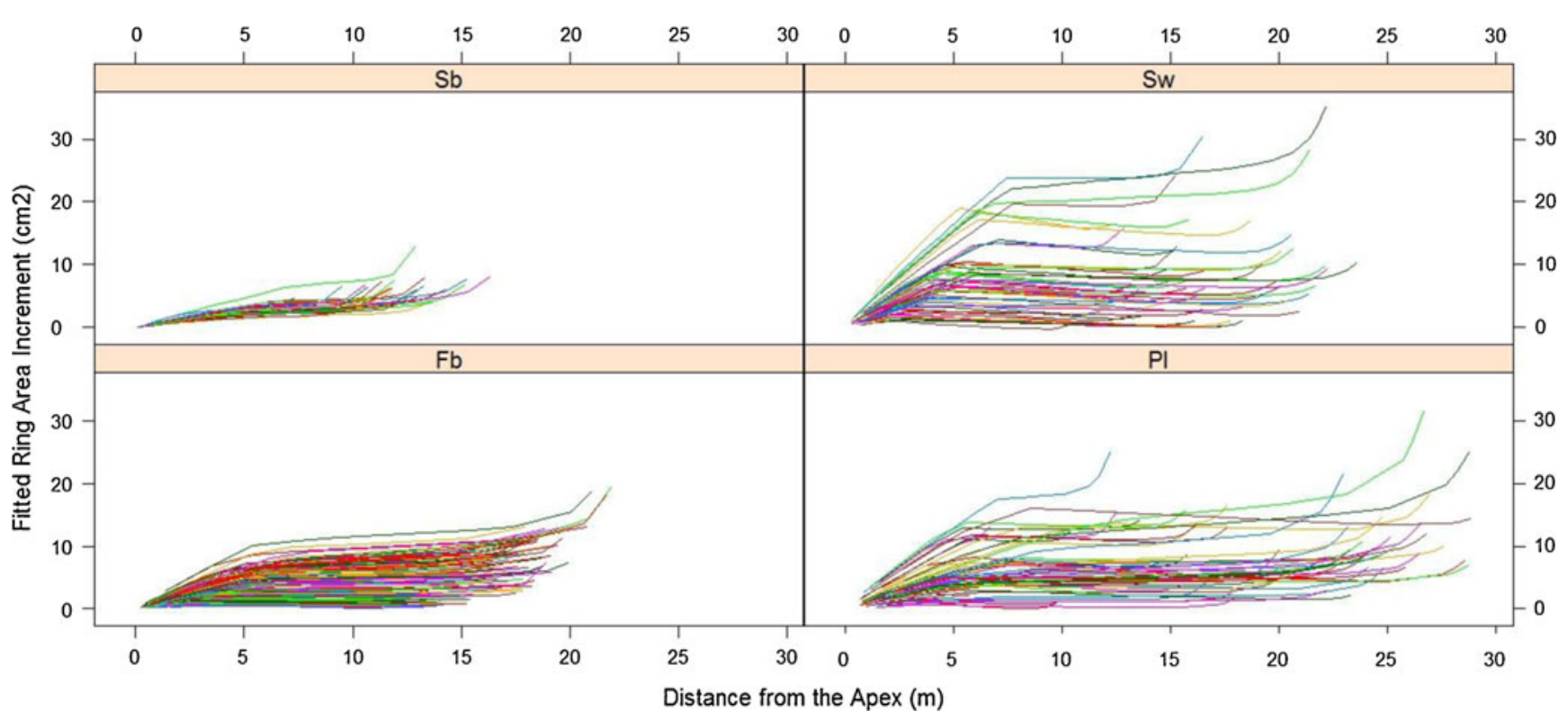

Fig 3 Spaghetti plots of predicted ring area increment (in square centimeters) calculated using Eq. 4 against distance from the apex (in meters): white spruce $(S w)$, black spruce $(S b)$, balsam fir $(F b)$, and lodgepole pine $(P l)$

The second component of Eqs. 1 to 4 was a function of DBCB (Distance Below Crown Base) and was additive from the effective crown base to the ground level. In Eqs. 3 and 4, the slope coefficient of DBCB in the middle component was a linear function of relative tree height $(\mathrm{RTH})$. The fixed effect parameter values of this function were always significantly different from 0 , which indicated that ring area increment below the crown was not constant (Table 3).

The third component of Eqs. 1 to 4, which describes butt swell, was a negative exponential function of RDH and was additive along the entire length of the tree. The negative sign and large magnitude of the $c_{1}$ coefficient, however, resulted in a rapid decline of the butt swell component with RDH.

The estimated magnitude of $c_{1}$ was substantially greater in the mixed effects analysis (Eq. 4), resulting in a greater butt swell close to the ground but also a more rapid decline in this component with RDH. The value of $c_{1}(-24.04)$ estimated for Eq. 4 (Table 3), means that this component declined to $10 \%$ of the ground level value at a $\mathrm{RDH}$ of 0.096 . In contrast, the corresponding value of $c_{1}(-14.78)$ for Eq. 3 means that this component declined to $10 \%$ of the ground level value at a RDH of 0.156 . Positive values of the $c_{2}$ coefficient indicate that the magnitude of the butt swell component increased with crown length, and no differences in magnitude among species were detected by the preliminary analysis using indicator variables.

The model fit statistics (Table 4) indicate that by adding crown attributes (Eq. 2) to the base model (Eq. 1) the overall model fit improved by $11 \%$ (based on the coefficient of determination), and the subsequent inclusion of stand attributes (Eq. 3) improved the model by an additional $7 \%$. Finally, adding random effects at the tree level (Eq. 4) improved the model further by an additional $17 \%$, resulting in a final coefficient of determination of approximately $97 \%$.

Moreover, the decrease in AIC values (i.e., from 15,212 to 8,238 ) indicates that the models improved going from Eqs. 1 to 4 . Similarly, the ring area increment RMSE decreased from $2.832(54.7 \%)$ to $0.769 \mathrm{~cm}^{2}(14.9 \%)$, and the tree level volume increment RMSE decreased from 33.5 to $2.1 \%$. The distribution of the data points around the 1:1 line and the Lowess fitted through the residuals suggest that Eqs. 3 and 4 provided consistent and unbiased estimates of observed values (Fig. 2). Scattered plots of the studentized residuals were also checked at the species level and they indicated consistent and unbiased estimates of observed values.

Predicted ring area increment for Eq. 2 resulted in some negative values for 1 out of 263 trees $(0.4 \%)$, for Eq. 3 there were five trees with some negative values $(1.9 \%)$, and for Eq. 4 there were three trees with some negative values (1.1\%). These were mainly suppressed trees with low annual ring area increment along the stem $\left(<1 \mathrm{~cm}^{2}\right)$.

Spaghetti plots using Eq. 4, which incorporated tree level random effects, show greater variation among trees of the same species in the slope of ring area below the effective crown base, and also show more pronounced and variable butt swell (Fig. 3). Predicted and observed ring area values were compared for the individual trees of each species closest to the 25th, 50th, and 75th percentiles of tree volume increment for that species (Fig. 4). Large variation in the magnitude and pattern of measured ring area was apparent, with some trees showing a distinct breakpoint near the effective crown base (e.g., Fig. 4a), but others not (e.g., Fig. 4g). The general improvement in model fit from Eqs. 1 to 3 is evident in Fig. 4, as is the very close fit of Eq. 4 in all cases. 

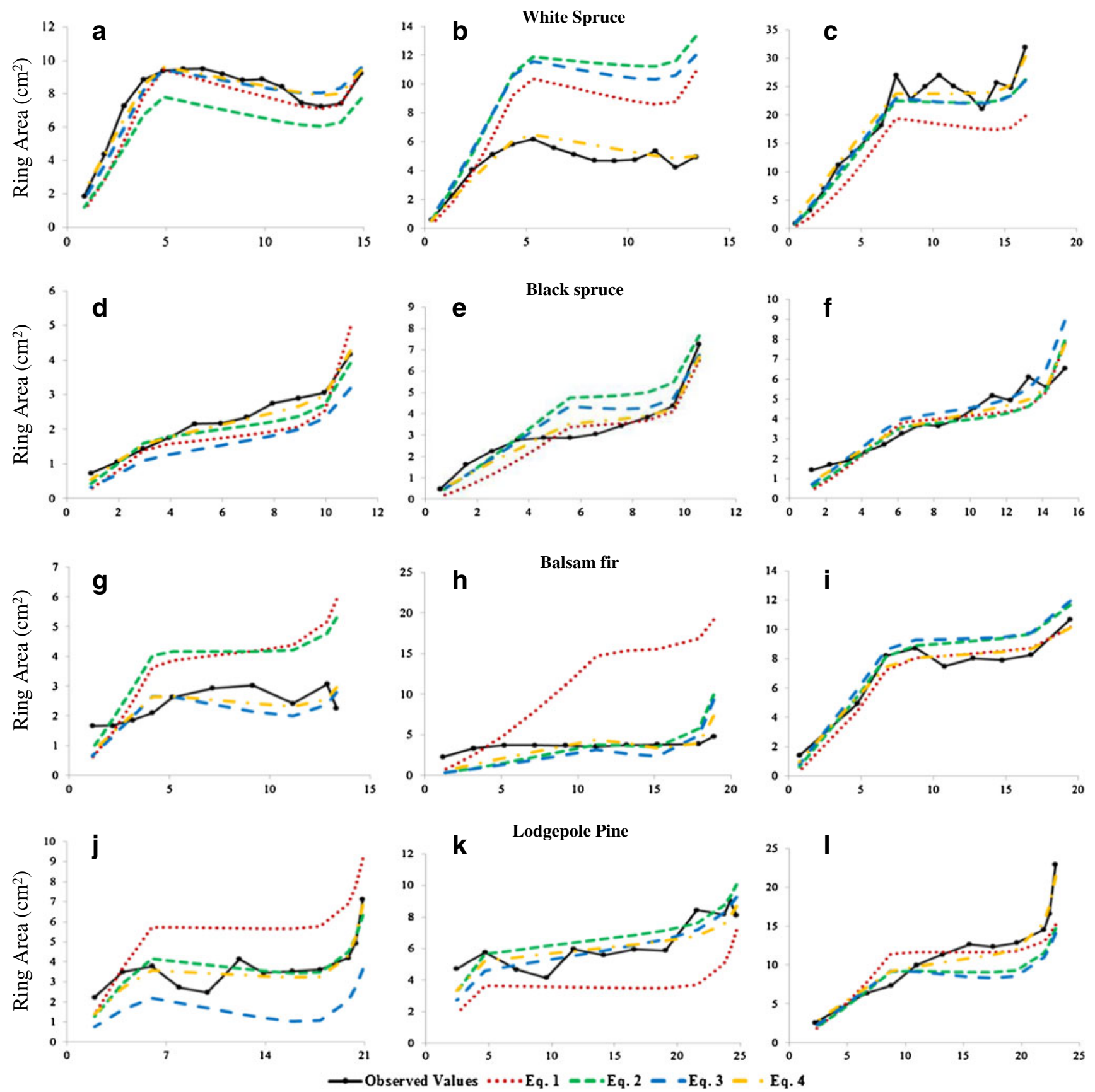

Distance from the Apex (m)

Distance from the Apex (m)

Distance from the Apex (m)

Fig. 4 The trees presented were selected by choosing the closest trees to the 25 th $(\mathbf{a}, \mathbf{d}, \mathbf{g}, \mathbf{j}), 50$ th $(\mathbf{b}, \mathbf{e}, \mathbf{h}, \mathbf{k})$, and 75 th $(\mathbf{c}, \mathbf{f}, \mathbf{i}, \mathbf{l})$ percentiles of tree volume increment within each species. Observed and predicted values (Eqs. 1-4) for each species are presented

\section{Discussion}

This study further supports the view that Pressler's law, as originally formulated, is an oversimplification of the pattern of ring area along the tree stem (Deleuze and Houllier 1995), both within and below the crown. Ring area does consistently increase from the tree apex in the upper two thirds of the crown region, but the location of the breakpoint averages one third of a crown length above the crown base. In Eq. 4, the increase in ring area with distance from the tree apex was slightly less than linear, whereas the amount of foliage in the upper crown often increases more than linearly with distance from the apex (Gilmore and Seymour 1997).

Nonlinearity in the relationship between ring area at a point and foliage area above that point was also noted by Kershaw and Maguire (2000). The location of the breakpoint 
in ring area profile may be related to the position of the maximum of the distribution of foliage (Kershaw and Maguire 2000), which typically occurs in the mid to lower crown (Maguire and Bennett 1996; Gilmore and Seymour 1997). The lower part of the crown has less productive branches because their foliage is more shaded and under greater competition from neighboring trees (Sprugel et al. 1991), possibly accounting for decoupling of ring area and foliage amount below the breakpoint represented by the crown factor.

These aspects of ring area distribution are to some extent contradictory to Pressler's law since ring area at any point within the crown is not uniquely proportional to the quantity of foliage above it. More broadly, however, the significant effects of crown radius and site index on the slope of ring area with distance inside the crown do indicate that larger and more productive crowns result in disproportionately greater ring area (Groot and Saucier 2008).

Pressler's law implies constant ring area increment below the base of the live crown, an outcome that is not corroborated by this or previous studies (Osawa et al. 1991; Kershaw and Maguire 2000). The decrease in the slope of the ring area profile below the crown as crown radius and relative tree height decrease, and as crown ratio increases, is consistent with the widely observed reduction in stem taper with decreasing crown class (Larson 1963). Although ring area is not constant below the crown base, the population-level values (fixed effects) of the slope of the ring area profile (Eq. 4) are relatively small, compared with average observed ring area at the effective crown base of 8.0, 2.4, 3.5, and $6.2 \mathrm{~cm}^{2}$ for white spruce, black spruce, balsam fir and lodgepole pine, respectively. Considering all of the combinations of independent variables in the data, the slope of the second component was most negative for white spruce (average of $-0.17 \mathrm{~cm}^{2} \mathrm{~m}^{-1}$ ) and most positive for black spruce (average of $+0.14 \mathrm{~cm}^{2} \mathrm{~m}^{-1}$ ). The combination of independent variables that resulted in the largest magnitude estimate for slope $\left(-0.35 \mathrm{~cm}^{2} \mathrm{~m}^{-1}\right)$ was for a lodgepole pine with low $\mathrm{RTH}, \mathrm{CrR}$, and CrT.

It is not possible to determine whether species differences in the slope of the ring area profile are inherent species differences in the ratio between photosynthetic and respiration tissues (e.g., Lavigne 1991) or a result of differing stand structure, history or site quality. The random effects included in Eq. 4 indicate that there is considerable tree-to-tree variation in the slope of the ring area profile, which is not explained by the tree and stand variables included in the analysis.

The increase in ring area near the tree base (butt swell) is a prominent feature of the ring area profile that is not described by Pressler's law. While the butt swell may represent a significant biomass component, typically the stem base is a region of poor wood quality (Xu and Walker 2004; Watt et al.
2011). The coefficient $\left(c_{1}\right)$ of the negative exponential function in the butt swell component results in high curvilinearity and a rapid decline of this component with relative disk height. The increased magnitude of butt swell with greater crown length is likely a manifestation of the role that butt swell plays in the mechanical stability of trees since larger crowns induce greater stress through wind loading (Larson 1963). The lack of species effect in the butt swell component may indicate that the unexplained variation at the bottom of the tree is related to microsite factors such as slope, terrain, and soil characteristics.

The mixed effects model described a butt swell component that was substantially more pronounced and that declined more rapidly with relative disk height than the fixed effects models. The fixed effects models appear to overestimate the relative disk height to which butt swell is present; taper models suggest that butt swell in northern conifers is significant at relative disk heights below 0.05 (Fonweban et al. 2011).

Mixed effects models have become popular options for better prediction and local calibration while accounting for data structure and lack of independence (e.g., Fang and Bailey 2001). Our results provide further evidence in this regard, such as superior performance and residual behavior for Eq. 4 (Fig. 2). However, improvements provided by inclusion of mixed effects should not negate the initial development of robust and biologically relevant fixed-effects models (Kershaw et al. 2009). Users of mixed effects models need to be aware that subject-specific predictions are conditional on the availability of additional subject observations (Huang et al. 2009), such previous subject measurements may not always be readily available or feasible to obtain (Groom et al. 2012). In the absence of previous information only population-averaged predictions can be made, and any predictions should be limited to populations with characteristics similar to the sample data.

Knowledge of the longitudinal distribution of ring area increment is fundamental to better understanding the linkage between tree growth and wood quality. This study has increased knowledge about the role of the tree crown, intraspecific competition and site quality on the amount and distribution of xylem increment along the tree stem. This knowledge can be incorporated into existing (e.g., Houllier et al. 1995) or new individual tree growth and wood quality models. The independent variables required for such models can be obtained from traditional measurements of forestry sample plots, but an emerging possibility is that rapidly evolving remote sensing methods such as high-density LiDAR and high resolution digital imagery will provide estimates of individual tree height and crown dimensions (Leckie et al. 2003). This raises the opportunity of supplying combined tree growth and wood quality models, and forest inventory with inputs obtained from remote sensing at the 
individual tree scale. The resulting outputs with individual tree or within tree resolution and with both growth and wood quality information will support better forest management and forest utilization decision making (Li 2009).

More work is required to generalize the model developed in this study. Although the model form is evidently valid for a number of species, model parameters must be estimated using data from a wider range of conditions for broad application. The lodgepole pine results show that site quality influences ring area increment, and this aspect needs to be further investigated for all species. In addition, for generality, the model must be fitted with data from a wide range of stand ages, competitive conditions and crown dimensions. Effective model application will also require validation using an independent data set.

Acknowledgments Special thanks go to: Mr. Jim Goudie of the BC Ministry of Forests, Lands, and Natural Resource Operations for providing the lodgepole pine data; Dr. Doug Pitt of the Canadian Forest Service for supplying the balsam fir data, Mr. Andrew Innerd for sharing white spruce samples; Mr. Ian Cameron of Azura Formetrics for assistance with the statistical analysis; and Mr. Gurp Thandi of the Canadian Forest Service for creating the map presented in this manuscript. The authors would also like to thank the two anonymous reviewers for providing constructive comments and suggestions.

Funding Funding of this research was provided by the Canadian Wood Fibre Centre (Canadian Forest Service).

\section{References}

Barczi J-F, Rey H, Caraglio Y, De Reffye P, Barthélémy D, Dong QX, Fourcaud T (2008) AmapSim: a structural whole-plant simulator based on botanical knowledge and designed to host external functional models. Ann Bot 101:1125-1138

Bevilacqua E, Puttock D, Blake TJ, Burgess D (2005) Long-term differential stem growth responses in mature eastern white pine following release from competition. Can J For Res 35:511-520

Burnham KP, Anderson DR (1998) Model selection and inference: a practical information-theoretic approach. Springer, New York, $353 \mathrm{pp}$

Courbet F (1999) A three-segmented model for the vertical distribution of annual ring area. Application to Cedrus atlantica Manetti. For Ecol Manage 119:177-194

Cruickshank M (2002) Accuracy and precision of measuring crosssectional area in stem disks of Douglas-fir infected by Armillaria root disease. Can J For Res 32:1542-1547

Deleuze C, Houllier F (1995) Prediction of stem profile of Picea abies using a process-based tree growth model. Tree Phys 15:113-120

Deleuze C, Houllier F (2002) A flexible radial increment taper equation derived from a process-based carbon partitioning model. Ann For Sci 59:141-154

Fang Z, Bailey RL (2001) Nonlinear mixed effects modeling for slash pine dominant height growth following intensive silvicultural treatments. For Sci 47:287-300

Farrar JL (1961) Longitudinal variation in the thickness of the annual ring. For Chron 37:323-330, 349

Fonweban J, Gardiner B, Macdonald E, Auty D (2011) Taper functions for Scots pine (Pinus sylvestris L.) and Sitka spruce
(Picea sitchensis (Bong.) Carr.) in Northern Britain. Forestry 84:49-60

Gaffrey D, Sloboda B (2001) Three mechanics, hydraulics and needlemass distribution as a possible basis for explaining the dynamics of stem morphology. J For Sci 47:241-254

Gilmore DW, Seymour RS (1997) Crown architecture of Abies balsamea from four canopy positions. Tree Phys 17:71-980

Groom JD, Hann DW, Temesgen H (2012) Evaluation of mixed-effects models for predicting Douglas-fir mortality. For Ecol Manage 276:139-145

Groot A (2002) Is uneven-aged silviculture applicable to peatland black spruce (Picea mariana) in Ontario, Canada? Forestry $75: 437-442$

Groot A, Saucier J-P (2008) Volume increment efficiency of Picea mariana in northern Ontario, Canada. For Ecol Manage 255:1647-1653

Houllier F, Leban J-M, Colin F (1995) Linking growth modelling to timber quality assessment for Norway spruce. For Ecol Manage 74:91-102

Huang S, Wiens DP, Yang Y, Meng SX, Vanderschaaf CL (2009) Assessing the impacts of species composition, top height and density on individual tree height prediction of quaking aspen in boreal mixedwoods. For Ecol Manage 258:1235-1247

Hyink DM, Zedaker SM (1987) Stand dynamics and the evaluation of forest decline. Tree Phys 3:17-26

Ikonen VP, Kellomäki P, Väisänen H, Peltola H (2006) Modelling the distribution of diameter growth along the stem in Scots pine. Trees 20:391-402

Jozsa LA, Middleton GR (1994) A discussion of wood quality attributes and their practical implications. Special Publication No. SP-34, Forintek Canada Corp., Vancouver. $51 \mathrm{p}$

Kershaw JA Jr, Maguire DA (2000) Influence of vertical foliage structure on the distribution of stem cross-sectional area increment in western hemlock and balsam fir. For Sci 46:86-94

Kershaw JA Jr, Benjamin JG, Weiskittel AR (2009) Approaches for modeling vertical distribution of maximum knot size in black spruce: a comparison of fixed- and mixed-effects nonlinear models. For Sci 55:230-237

Labyak LF, Schumacher FX (1954) The contribution of its branches to the main-stem growth of Loblolly pine. J For 52:333-337

Larson PR (1963) Stem form development of forest trees. For Sci Monogr 5

Lavigne MB (1991) Effects of thinning on allocation of growth and respiration in young stands of balsam fir. Can J For Res 11:459 464

Leckie D, Gougeon F, Hill D, Quinn R, Armstrong L, Shreenan R (2003) Combined high-density Lidar and multispectral imagery for individual tree crown analysis. Can J Remote Sens 29:633-649

Li C (2009) Toward full, multiple, and optimal wood fibre utilization: a modeling perspective. For Chron 85:377-381

Maguire DA, Bennett WS (1996) Patterns in vertical foliage distribution of foliage in young coastal Douglas-fir. Can J For Res 26:1991-2005

Mansfield SD, Parish R, Goudie JW, Kang K-Y (2007) The effects of crown ratio on the transition from juvenile to mature wood production in lodgepole pine in western Canada. Can J For Res 37:1450-1459

Max TA, Burkhart HE (1976) Segmented polynomial regression applied to taper equations. For Sci 22:283-289

Mitchell KJ (1975) Dynamics and simulated yield of Douglas-fir. For Sci Monogr 17

Newberry JD (1991) A note on Carmean's estimate of height from stem analysis data. For Sci 37:368-369

Osawa A, Ishizuka M, Kanazawa Y (1991) A profile theory of tree growth. For Ecol Manage 41:33-63 
Ottorini J-M, Le Goff N, Cluzeau C (1996) Relationships between crown dimensions and stem development in Fraxinus excelsior. Can J For Res 26:394-401

Panshin AJ, de Zeuw C (1970) Textbook of wood technology. McGraw-Hill, New York, 705 p

Pitt D, Lanteigne L (2008) Long-term outcome of precommercial thinning in northwestern New Brunswick: growth and yield of balsam fir and red spruce. Can J For Res 38:592-610

Pinheiro JC, Bates DM, DebRoy S, Sarkar D, and the R Core team (2009) NLME: Linear and Nonlinear Mixed Effects Models. R package version 3.1-96

Pinherio JC, Bates DM (2000) Mixed-Effects Models in S and S-Plus. Springer-Verlag, New York

Pressler MR (1864) Das Gesetz der Stammbildung. Arnoldische Buchhandlung, Leipzig, $153 \mathrm{p}$
Saranpää P (2003) Wood density and growth. In: Barnett, J.R. and Jeronimidis, G (eds) Wood quality and its biological basis. CRC Press, Boca Raton, pp. 87-117

Sprugel DG, Hinckley TM, Schaap W (1991) The theory and practice of branch autonomy. Annu Rev Ecol Syst 22: 309334

Watt MS, Zoric B, Kimberley MO, Harrington J (2011) Influence of stocking on radial and longitudinal variation in modulus of elasticity, microfibril angle, and density in a 24-yearold Pinus radiate thinning trial. Can J For Res 41:14221431

Weiner J (1984) Neighbourhood interference amongst Pinus rigida individuals. J Ecol 72:183-195

$\mathrm{Xu}$ P, Walker JCF (2004) Stiffness gradients in radiata pine trees. Wood Sci Technol 38:1-9 